\title{
Pengaruh Experiential Marketing dan Kualitas Pelayanan terhadap Loyalitas Nasabah dengan Kepuasan Sebagai Variabel Intervening pada BMT di Kota Palembang
}

\author{
Ahmad Rendi ${ }^{1 *}$ \\ ${ }^{1}$ UIN Raden Fatah Palembang, Indonesia
}

\begin{abstract}
Abstrak: Penelitian ini bertujuan untuk mengetahui pengaruh experiental marketing dan kualitas pelayanan terhadap loyalitas nasabah dengan kepuasan sebagai variabel intervining. Metode penelitian menggunakan pendekatan kuantitatif dengan objek penelitian pada BMT Insan Mulia Palembang, BMT Mitra Khazanah Palembang, dan BMT Tarbiyah Palembang. Data dikumpulkan dengan kuisioner dengan analisis deskriptif dan jalur. Penelitian ini menyimpulkan bahwa kualitas pelayanan berpengaruh terhadap variabel loyalitas nasabah dengan variabel kepuasan nasabah sebagai variabel intervening pada BMT di Kota Palembang berdasarkan nilai t hitung sebesar 2,511 lebih besar dari t tabel 1,985.
\end{abstract}

Kata Kunci: experiental marketing, kualitas pelayanan, kepuasan nasabah, loyalitas nasabah

\begin{abstract}
This study aims to determine the effect of experiential marketing and service quality on customer loyalty with satisfaction as an intervining variable. The research method uses a quantitative approach with the object of research at BMT Insan Mulia Palembang, BMT Mitra Khazanah Palembang, and BMT Tarbiyah Palembang. Data were collected by questionnaire with descriptive and path analysis. This study concludes that service quality has an effect on customer loyalty variable with customer satisfaction variable as an intervening variable at BMT in Palembang City based on the $t$ count value of 2.511 which is greater than $t$ table 1.985 .
\end{abstract}

Keywords: experiential marketing, service quality, customer satisfaction, customer loyalty

\section{Pendahuluan}

Baitul Mal wat Tamwil (BMT) termasuk salah satu dari Lembaga Keuangan Mikro Syariah (LKMS) yang sedang berkembang di kalangan masyarakat menengah ke bawah bahkan golongan masyarakat menengah ke atas. Layanan atau jasa BMT seringkali digunakan dan banyak diakses oleh masyarakat kecil yang membutuhkan dana untuk menjalankan suatu usaha (modal kerja). BMT berperan sebagai mitra usaha dengan bagi hasil atau margin yang proporsional. BMT juga dianggap memiliki keunggulan, yaitu kemudahan dan fleksibelitas dalam mengajukan pembiayaan serta pemberian bagi hasil investasi mudarabah yang sangat kompetitif. sebagaimana layaknya lembaga keuangan pada umumnya yang melaksanakan fungsi social oriented (berorientasi sosial), BMT juga berfungsi menghasilkan keuntungan (profit oriented). Kemunculan lembaga Baitul Mal wat Tamwil, yang melakukan kegiatannya berdasar prinsip-prinsip syariah dirasakan betul bagi umat dapat memenuhi kebutuhan, tidak saja karena

\footnotetext{
* Corresponding Author: Ahmad Rendi (arendi192@gmail.com). UIN Raden Fatah Palembang, Indonesia
} 
sistemnya yang sesuai syariat, namun juga fungsi sosial dan ekonomi. Oleh karena itu, kemudian bermunculan lembaga-lembaga keuangan mikro syariah dengan nama generik BMT yang banyak dimotori oleh aktivis atau Jamaah masjid atau dari organisasi kemasyarakatan seperti Muhammadiyah, Nahdhatul Ulama, Persis dan sebagainya, serta umat lain secara perorangan atau kelompok

Kepuasan pelanggan sangat perlu untuk diperhatikan oleh perusahaan karena akan berdampak pada kinerja penjualan. Kotler dan Armstrong (1997) menyatakan bahwa, pelanggan yang merasa puas akan membeli ulang, dan mereka akan memberi tahu orang lain mengenai pengalaman baik tentang produk itu. Kepuasan pelanggan berkontribusi pada sejumlah aspek krusial, seperti terciptanya loyalitas pelanggan, meningkatnya reputasi perusahaan, berkurangnya elastisitas harga, berkurangnya biaya transaksi masa depan, dan meningkatnya efisiensi dan produktivitas karyawan (Tjiptono \& Chandra, 2011). Berbagai aspek yang harus diperhatikan untuk membangun loyalitas pelanggan antara lain kepuasan pelanggan, keyakinan dalam beragama (religiusitas), dan kualitas pelayanan. Untuk mendapatkan loyalitas pelanggan, perusahaan perlu melakukan strategi pemasaran yang tepat agar dapat mempengaruhi loyalitas pelanggannya. Menurut Lewis dan Booms, kualitas layanan atau kualitas jasa merupakan ukuran seberapa bagus tingkat layanan yang diberikan mampu sesuai dengan ekspektasi pelanggan (Tjiptono \& Chandra, 2011).

Pelayanan nasabah diberikan oleh berbagai pihak seperti customer service yang betugas untuk memberikan pelayanan dan membina pelayanan dan melayani para nasabah serta selalu berusaha menarik dengan cara meyakinkan para calon nasabah dengan baik. Selain itu pelayanan juga diberikan oleh teller yang lebih banyak berhubungan dengan nasabah dalam bidang penyetoran dan penarikan uang nasabah. Daya tanggap dari seorang karyawan dalam merespon dan membantu nasabah merupakan suatu alat pengukur sederhana dalam kualitas pelayanan yang ada di BMT tersebut. Sehingga apabila sebuah lembaga mempunyai kualitas pelayanan yang baik juga akan mempengaruhi kepuasan dari para nasabah itu sendiri dan akan memunculkan sifat loyal dari nasabah. Nasabah saat ini menginginkan sesuatu yang lebih dari sekedar sebuah produk atau jasa, mereka menginginkan pengalaman yang menyenangkan untuk kepuasan maksimal sesuai yang diharapkan. Menurut Schmitt (2011) pendekatan experiential makreting merupakan pendekatan pemasaran yang menyediakan pengalaman melalui berbagai media (experience provider). Experiential marketing merupakan sebuah pendekatan baru untuk memberikan informasi mengenai merek dan produk. Dalam pendekatan ini pemasar menciptakan jasa atau produk yang dapat menstimulus konsumen melalui pancaindera, hati dan pikiran sehingga membentuk pengalaman. Pengalaman yang diberikan perusahaan kemudian mampu menyentuh emosional pelanggan akan menambah kepuasan tersendiri bagi pelanggan. Dengan demikian perusahaan harus memaksimumkan pengalaman yang menyenangkan bagi pelanggan dan meminimumkan pengalaman kurang menyenangkan bagi pelanggan.

Pelayanan yang baik kepada pelanggan akan dapat membuat citra dan kesan positif terhadap perusahaan. Pelayanan yang baik mendorong minat pelanggan untuk menggunakan kembali jasa tersebut sehingga tercipta loyalitas. Salah satu cara untuk membuat berbeda dari sebuah perusahaan jasa adalah memberikan jasa dengan kualitas yang lebih tinggi dari para pesaingnya secara konsisten. 
Kuncinya adalah memenuhi atau melebihi harapan kualitas jasa pelanggan sasaran (Kotler, 1997). Menurut Parasuraman (1988), bahwa ada 5 dimensi penentu kualitas jasa, yaitu reliability (keandalan), responsiveness (daya tanggap), assurance (jaminan), emphaty (empati), dan tangible (kasat mata). Kondisi yang selalu berubah mengakibatkan sebuah lembaga mengalami kesulitan didalam membentuk dan menciptakan para nasabah yang loyal. Dengan kondisi BMT yang mempunyai produk yang relatif sedikit dan tetap, strategi pemasaran yang masih bersifat lokal, serta dipromosikan yang masih kurang gencar serta persaingan yang cukup ketat menyebabkan BMT kurang dikenal oleh masyarakat secara umum. Hal ini menjadi fenomena yang sangat menarik untuk mengetahui tingkat pelayanan dan kepuasan nasabah dan pada akhirnya akan berdampak pada loyalitas dari nasabahnya. BMT yang berada di kota Palembang merupakan BMT yang mempunyai kondisi sebagaimana yang dipaparkan diatas, oleh karena itu peneliti menjadikan BMT sebagai lembaga yang patut untuk diteliti.

Dari fenomena di atas, dimana kenaikan jumlah nasabah di tiga tahun terakhir ini menjadi fenomena yang menarik, mengingat bahwa BMT merupakan lembaga keuangan mikro dengan berbagai keterbatasan baik berupa modal yang sedikit, promosi yang masih sederhana serta minimnya fasilitas yang dimiliki BMT mampu untuk menarik masyarakat menjadi nasabahnya. Hal ini tentunya memjadikan BMT untuk berusaha lebih maksimal dalam memberikan pelayanan kepada nasabah serta memberikan pengalaman yang lebih menyenangkan bagi nasabah sehingga dapat menutupi kekurangan BMT yang menjadi keluhan nasabah saat ini.

\section{Metode Penelitian}

Metode penelitian yang digunakan adalah kuantitatif. Jenis data kuantitatif dalam penelitian ini merupakan jenis data kuantitatif yang diperoleh melalui kuisioner yang dibagikan kepada nasabah BMT Insan Mulia, BMT Mitra Khazanah dan BMT Tarbiyah di kota Palembang. Pengambilan sampel menggunakan teknik purposive sampling berjumlah 100 responden dari 6.107 populasi. Instrumen penelitian dilakukan dengan uji validitas, uji reliabilitas, uji normalitas, analisis jalur, dan uji hipotesis.

\section{Hasil dan Pembahasan}

\section{Hasil Uji Validitas}

Berikut ini adalah hasil dari pengujian validitas data penelitian:

Tabel 1. Uji Validitas

\begin{tabular}{|c|c|c|c|c|}
\hline Variabel & $\begin{array}{c}\text { Item } \\
\text { Pertanyaan }\end{array}$ & \begin{tabular}{|} 
Corrected Item \\
Pertanyaan \\
Total \\
Corelation
\end{tabular} & $r$ tabel & Ket. \\
\hline \multirow{10}{*}{$\begin{array}{l}\text { Experiential } \\
\text { Marketing }\end{array}$} & EM_1 & 0,459 & 0,1966 & Valid \\
\hline & EM_2 & 0,651 & 0,1966 & Valid \\
\hline & EM_3 & 0,778 & 0,1966 & Valid \\
\hline & EM_4 & 0,810 & 0,1966 & Valid \\
\hline & EM_5 & 0,802 & 0,1966 & Valid \\
\hline & EM_6 & 0,388 & 0,1966 & Valid \\
\hline & EM_7 & 0,734 & 0,1966 & Valid \\
\hline & EM_8 & 0,712 & 0,1966 & Valid \\
\hline & EM_9 & 0,819 & 0,1966 & Valid \\
\hline & EM_10 & 0,689 & 0,1966 & Valid \\
\hline \multirow{10}{*}{\begin{tabular}{|l} 
Kualitas \\
Pelayanan
\end{tabular}} & KP_1 & 0,568 & 0,1966 & Valid \\
\hline & KP_2 & 0,533 & 0,1966 & Valid \\
\hline & KP_3 & 0,495 & 0,1966 & Valid \\
\hline & KP_4 & 0,624 & 0,1966 & Valid \\
\hline & KP_5 & 0,633 & 0,1966 & Valid \\
\hline & KP_6 & 0,591 & 0,1966 & Valid \\
\hline & KP_7 & 0,456 & 0,1966 & Valid \\
\hline & KP_8 & 0,592 & 0,1966 & Valid \\
\hline & KP_9 & 0,533 & 0,1966 & Valid \\
\hline & KP_10 & 0,562 & 0,1966 & valid \\
\hline
\end{tabular}




\begin{tabular}{|c|l|c|c|c|}
\hline Variabel & $\begin{array}{c}\text { Item } \\
\text { Pertanyaan }\end{array}$ & $\begin{array}{c}\text { Corrected Item } \\
\text { Pertanyaan } \\
\text { Total } \\
\text { Corelation }\end{array}$ & r tabel & Ket. \\
& & & & \\
\hline \multirow{5}{*}{ Kepuasan } & K_1 & 0,864 & 0,1966 & Valid \\
\cline { 2 - 5 } & K_2 & 0,871 & 0,1966 & Valid \\
\cline { 2 - 5 } & K_3 & 0,709 & 0,1966 & Valid \\
\cline { 2 - 5 } & K_4 & 0,373 & 0,1966 & Valid \\
\cline { 2 - 5 } & K_5 & 0,240 & 0,1966 & Valid \\
\hline \multirow{5}{*}{ Loyalitas } & Ly_1 & 0,741 & 0,1966 & Valid \\
\cline { 2 - 5 } & Ly_2 & 0,724 & 0,1966 & Valid \\
\cline { 2 - 5 } & Ly_3 & 0,808 & 0,1966 & Valid \\
\cline { 2 - 5 } & Ly_4 & 0,489 & 0,1966 & Valid \\
\cline { 2 - 5 } & Ly_5 & 0,428 & 0,1966 & Valid \\
\hline
\end{tabular}

Sumber: Data primer yang diolah, 2021

Dari tabel 1 di atas dapat diketahui bahwa masing-masing item pernyataan memiliki $r_{\text {hitung }}>r$ tabel $(0,1966)$ dan bernilai positif. Dengan demikian butir pernyataan tersebut dinyatakan valid.

\section{Hasil Uji Reliabilitas}

Hasil uji reliabilitas disajikan pada tabel 2 berikut:

Tabel 2. Hasil Uji Reliabilitas

\begin{tabular}{|l|l|c|c|}
\hline \multicolumn{1}{|c|}{ Variabel } & $\begin{array}{l}\text { Reliabilitas } \\
\text { Coefficient }\end{array}$ & Alpha & Ket. \\
\hline Experiential & 10 item & 0,87 & Reliabel \\
Marketing & pernyataan & 8 & \\
\hline Kualitas Pelayanan & 10 item & 0,75 & Reliabel \\
& pernyataan & 3 & \\
\hline Kepuasan & 5 item & 0,61 & Reliabel \\
& pernyatan & 5 & \\
\hline Loyalitas & 5 item & 0, & Reliabel \\
& pernyataan & 637 & \\
\hline
\end{tabular}

Sumber: Data primer yang diolah, 2021

Tabel 2 di atas menunjukkan nilai Cronbach's Alpha atas semua variable yang digunakan dalam penelitian $>0,60$. Dengan demikian, dapat di simpulkan bahwa pernyataan dalam kuesioner ini reliabel karena mempunyai nilai Cronbach's Alpha lebih besar dari 0,60.

\section{Hasil Uji Normalitas}

Hasil uji normalitas disajikan pada tabel 3 berikut:

Tabel 3. Hasil Uji Normalitas

\begin{tabular}{|l|l|l|}
\hline & $\begin{array}{l}\text { Unstandardized } \\
\text { Residual } \\
\text { Persamaan 1 }\end{array}$ & $\begin{array}{l}\text { Unstandardized } \\
\text { Residual } \\
\text { Persamaan 2 }\end{array}$ \\
\hline $\begin{array}{l}\text { Asymp. } \\
\text { Sig. } \\
(2- \\
\text { tailed) }\end{array}$ & 0,334 & 0,412 \\
\hline
\end{tabular}

Sumber: Data primer yang diolah, 2021

Berdasarkan grafik normal P-P Plot pada kedua persamaan tersebut menunjukkan bahwa penyebaran data mengikuti garis normal (garis lurus) dan hal yang sama itu pun ditunjukkan pada tabel 3 uji Kolgomorov Smirnov menunjukkan bahwa data tersebut berdistribusi normal yakni Asymp. Sig. lebih besar dari 0,05. Dengan demikian dapat disimpulkan bahwa residual data berdistribusi normal dan model regresi telah memenuhi asumsi normalitas.

\section{Hasil Analisis Path}

\section{Analisis Jalur Struktur 1}

Gambar 1. Analisis Jalur Struktur 1

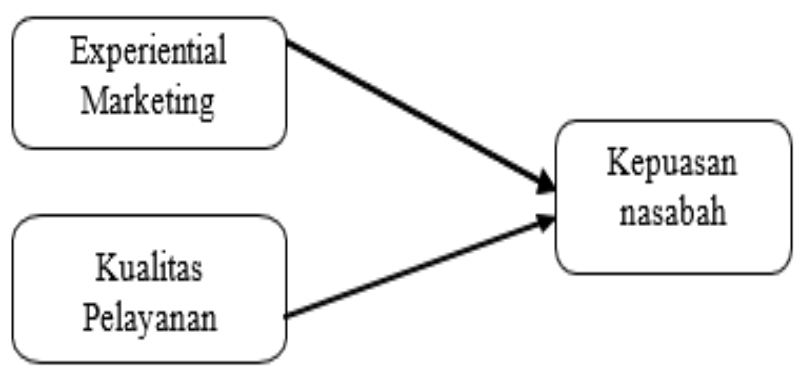


Tabel 4. Koefisien Determinasi Struktur I

\begin{tabular}{|l|c|}
\hline Model & R Square \\
\hline & 0,236 \\
\hline
\end{tabular}

Sumber: Data diolah dari lampiran

Pada tabel 4 di atas didapat nilai R Square $\left(\mathrm{R}^{2}\right)$ sebesar 0,236. Angka tersebut menunjukan bahwa pengaruh experiential marketing dan kualitas pelayanan terhadap kepuasan nasabah secara simultan adalah $23,6 \%$, sedangkan sisanya sebesar $76,4 \% \quad(100 \%-23,6 \%)$ adalah kemungkinan terdapat aspek-aspek lain yang memiliki pengaruh terhadap variable kepuasan nasabah.

\section{Uji Simultan (Uji Statistik F)}

Pengujian hipotesis secara simultan bertujuan untuk mengukur besarnya pengaruh variabel eksogen secara bersama-sama terhadap variabel endogen. Hasil hipotesis dalam pengujian ini adalah:

Tabel 5. Analisis Varian (Anova) Struktur I

\begin{tabular}{|c|c|c|}
\hline $\begin{array}{c}\text { Regresion Residual } \\
\text { Total }\end{array}$ & F & Sig. \\
\hline & 14,987 & 0,000 \\
\hline
\end{tabular}

Sumber: Data diolah dari lampiran, 2021

Pada tabel 5 hasil uji F untuk hasil olah data regression residual total pada kuesioner BMT di kota Palembang dapat dilihat nilai $\mathrm{F}$ hitung sebesar 14,987 > F table 3,09 signifikansi sebesar 0,000 lebih kecil dari 0,05. Maka model regresi dapat digunakan untuk memprediksi variabel kepuasan nasabah atau dengan kata lain variable eksogen Experiental Marketing dan Kualitas pelayanan secara bersama-sama (simultan) berpengaruh signifikan terhadap variabel endogen kepuasan nasabah.

\section{Uji Parsial (Uji Statistik t)}

Pengujian hipotesis secara parsial bertujuan untuk mengukur besarnya pengaruh variabel eksogen secara parsial terhadap variabel endogen. Hasil hipotesis yang dalam pengujian ini adalah:

Tabel 6. Pengaruh Experiential Marketing dan Kualitas Pelayanan secara parsial terhadap kepuasan nasabah

\begin{tabular}{|c|c|c|c|}
\hline \multirow{2}{*}{ Model } & $\begin{array}{l}\text { Standardized } \\
\text { Coefficients }\end{array}$ & \multirow[t]{2}{*}{$\mathrm{t}$} & \multirow[t]{2}{*}{ Sig. } \\
\hline & Beta & & \\
\hline (Constant) & & 2,582 & 0,011 \\
\hline Experiential Marketing & 0,452 & 5,037 & 0,000 \\
\hline Kualitas Pelayanan & 0,260 & 2,897 & 0,005 \\
\hline
\end{tabular}

Sumber: Data diolah dari lampiran, 2021

Jika t-hitung > t-tabel, maka Ho ditolak dan Ha diterima dan sebaliknya t-hitung < t-tabel, maka Ho diterima dan Ha ditolak. Besarnya angka t-tabel dengan ketentuan $\alpha=0,05$ dan $\mathrm{df}=(\mathrm{n}-\mathrm{k})$ atau $(100-$ $3)=97$. Dari ketentuan tersebut diperoleh angka ttabel sebesar 1,984.

a. Pengaruh Experiential Marketing terhadap Kepuasan Nasabah

Berdasarkan hasil perhitungan, diperoleh angka t-hitung sebesar 5,037 > t-tabel sebesar 1,984, sehingga Ho ditolak dan Ha diterima. Artinya ada pengaruh antara experiential marketing terhadap kepuasan nasabah. Besarnya pengaruh experiential marketing terhadap kepuasan nasabah $=0,452$ atau 45,2\% dianggap signifikan dengan angka signifikansi $0,000<\alpha=0,05$.

b. Pengaruh Kualitas Pelayanan terhadap Kepuasan Nasabah

Berdasarkan hasil perhitungan, diperoleh angka t-hitung sebesar 2,897 > t-tabel sebesar 1,984, sehingga Ho ditolak dan Ha diterima. Artinya ada pengaruh antara kualitas pelayanan terhadap kepuasan nasabah. 
Besarnya pengaruh kualitas pelayanan terhadap kepuasan nasabah $=0,260$ atau $26 \%$ dianggap signifikan dengan angka signifikansi $0,000<\alpha=0,05$.

\section{Analisis Jalur Struktur II}

Gambar 2. Analisis Jalur Struktur 2

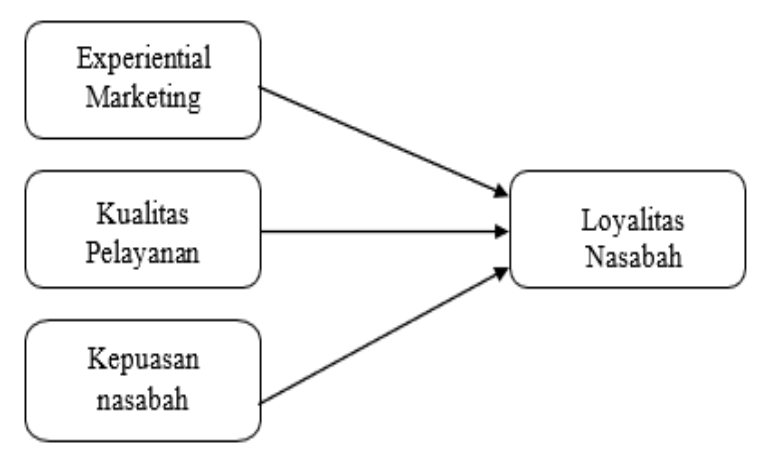

Tabel 7. Koefisien Determinasi Struktur I

\begin{tabular}{|c|c|}
\hline Model & R Square \\
\hline & 0,373 \\
\hline
\end{tabular}

Sumber: Data diolah dari lampiran, 2021

Pada tabel 7 di atas di dapat nilai R Square $\left(\mathrm{R}^{2}\right)$ sebesar 0,373. Angka tersebut menunjukan bahwa pengaruh experiential marketing, kualitas pelayanan dan kepuasan terhadap loyalitas secara simultan adalah $37,3 \%$, sedangkan sisanya sebesar $62,7 \%(100 \%-37,3 \%)$ adalah kemungkinan terdapat aspek-aspek lain yang memiliki pengaruh terhadap variable kepuasan nasabah.

\section{Uji Simultan (Uji Statistik F)}

Pengujian hipotesis secara silmultan bertujuan untuk mengukur besarnya pengaruh variabel eksogen secara bersama-sama terhadap variabel endogen. Hasil hipotesis dalam pengujian ini adalah:
Tabel 8. Analisis Varian (Anova) Struktur I

\begin{tabular}{|l|c|c|}
\hline \multicolumn{1}{|c|}{$\begin{array}{c}\text { Regresion Residual } \\
\text { Total }\end{array}$} & F & Sig. \\
\hline $\begin{array}{l}\text { BMT di Kota } \\
\text { Palembang }\end{array}$ & 19,061 & 0,000 \\
\hline
\end{tabular}

Sumber: Data diolah dari lampiran, 2021

Pada tabel 8 hasil uji $\mathrm{F}$ untuk hasil olah data regressione residual total pada kuesioner di BMT Insan mulia Palembang dapat dilihat nilai $\mathrm{F}$ hitung 19,06 > F table 3,09 signifikansi sebesar 0,000 lebih kecil dari 0,05. Maka model regresi dapat digunakan untuk memprediksi variabel loyalitas nasabah atau dengan kata lain variable eksogen experiental marketing, kualitas pelayanan dan kepuasan nasabah secara bersama-sama (simultan) berpengaruh signifikan terhadap variabel endogen loyalitas nasabah.

\section{Uji Parsial (Uji Statistik t)}

Pengujian hipotesis secara parsial bertujuan untuk mengukur besarnya pengaruh variabel eksogen secara parsial terhadap variabel endogen. Hasil hipotesis yang dalam pengujian ini adalah:

Table 9. Pengaruh Experiential Marketing dan Kualitas Pelayanan secara parsial terhadap Loyalitas Nasabah

\begin{tabular}{|c|c|c|c|}
\hline \multirow[t]{2}{*}{ Model } & $\begin{array}{l}\text { Standardized } \\
\text { Coefficients }\end{array}$ & \multirow[t]{2}{*}{$\mathrm{t}$} & \multirow[t]{2}{*}{ Sig. } \\
\hline & Beta & & \\
\hline (Constant) & & 0,105 & 0,917 \\
\hline Experiential Marketing & 0,207 & 2,253 & 0,027 \\
\hline Kualitas Pelayanan & 0,125 & 1,463 & 0,147 \\
\hline Kepuasan & 0,470 & 5,079 & 0,000 \\
\hline
\end{tabular}

Sumber: Data diolah dari lampiran, 2021

Jika t-hitung > t-tabel, maka Ho ditolak dan Ha diterima dan sebaliknya t-hitung $<\mathrm{t}$-tabel, maka Ho diterima dan Ha ditolak. Besarnya angka t-tabel dengan ketentuan $\alpha=0,05$ dan $\mathrm{df}=(\mathrm{n}-\mathrm{k})$ atau $(100$ $3)=97$. Dari ketentuan tersebut diperoleh angka ttabel sebesar 1,984. 
a. Pengaruh Experiential Marketing terhadap Loyalitas Nasabah

Berdasarkan hasil perhitungan, diperoleh angka t-hitung sebesar 2,253 > t-tabel sebesar 1,985, sehingga Ho ditolak dan Ha diterima. Artinya ada pengaruh antara experiential marketing terhadap loyalitas nasabah. Besarnya pengaruh experiential marketing terhadap loyalitas nasabah $=0,207$ atau $20,7 \%$ dianggap signifikan dengan angka signifikansi $0,000<\alpha=0,05$.

b. Pengaruh Kualitas Pelayanan terhadap Loyalitas Nasabah

c. Berdasarkan hasil perhitungan, diperoleh angka t-hitung sebesar 1,463 < t-tabel sebesar 1,984, sehingga Ho diterima dan Ha ditolak. Artinya tidak terdapat pengaruh antara kualitas pelayanan terhadap loyalitas nasabah. Besarnya pengaruh kualitas pelayanan terhadap loyalitas nasabah $=0,125$ atau $12,5 \%$ dianggap tidak signifikan dengan angka signifikansi $0,147>\alpha=0,05$.

d. Pengaruh Kepuasan Nasabah terhadap Loyalitas Nasabah

Berdasarkan hasil perhitungan, diperoleh angka t-hitung sebesar 5,079 > t-tabel sebesar 1,984, sehingga Ho ditolak dan Ha diterima. Artinya ada pengaruh antara Kepuasan nasabah terhadap loyalitas nasabah. Besarnya pengaruh kepuasan nasabah terhadap loyalitas nasabah $=0,470$ atau $47 \%$ dianggap signifikan dengan angka signifikansi $0,000<\alpha=0,05$.

\section{Uji Sobel}

Pengujian sobel yang dilakukan dalam penelitian ini adalah sebagai berikut:
1. Experiential Marketing (X1) terhadap Loyalitas Nasabah (Z) dengan Kepuasan Nasabah (Y) sebagai Variabel Intervening

Hitung besarnya standard eror pengaruh tidak langsung (indirect effect)

$$
\begin{gathered}
S a b=\sqrt{b^{2} s a^{2}+a^{2}} s b^{2}+s a^{2} s b^{2} \\
S a b= \\
\sqrt{(0,591)^{2}(0,035)^{2}+(0,177)^{2}} 0,116^{2}+ \\
\left(0,035^{2} 0,116^{2}\right. \\
=0,029
\end{gathered}
$$

Berdasarkan hasil sab ini, selanjutnya dapat menghitung nilai $t$ statistik pengaruh mediasi dengan rumus sebagai berikut: Perkalian koefisien $\boldsymbol{a} \boldsymbol{b}=(0,310)(0,336)$ sebesar 0,104. $t=\frac{0,104}{0,029}=3,589$

Hasil perhitungan diperoleh nilai $\mathrm{t}$ hitung sebesar 3,589 lebih besar dari t tabel dengan tingkat signifikansi 0,05 yaitu sebesar 1,98. Maka dapat disimpulkan bahwa ada pengaruh mediasi antara experiential marketing terhadap loyalitas nasabah melalui kepuasan nasabah.

2. Kualitas Pelayanan (X2) terhadap Loyalitas Nasabah (Z) dengan Kepuasan Nasabah (Y) sebagai Variabel Intervening

Hitung besarnya standard eror pengaruh tidak langsung (indirect effect)

$$
\begin{gathered}
S a b=\sqrt{b^{2} s a^{2}+a^{2}} s b^{2}+s a^{2} s b^{2} \\
S a b= \\
\sqrt{(0,591)^{2}(0,053)^{2}+(0,153)^{2}}(0,053)^{2}+ \\
(0,053)^{2}(0,116)^{2} \\
=0,036
\end{gathered}
$$

Berdasarkan hasil sab ini, selanjutnya dapat menghitung nilai $t$ statistik pengaruh mediasi dengan rumus sebagai berikut: Perkalian koefisien $\boldsymbol{a} \boldsymbol{b}=(0,153)(0,591)$ sebesar 0,090. $t=\frac{0,090}{0,036}=2,511$. 
Hasil perhitungan diperoleh nilai $\mathrm{t}$ hitung sebesar 2,511 lebih besar dari t tabel dengan tingkat signifikansi 0,05 yaitu sebesar 1,98 . Maka dapat disimpulkan bahwa ada pengaruh mediasi antara kualitas pelayanan terhadap loyalitas nasabah melalui kepuasan nasabah.

\section{Pembahasan}

\section{Pengaruh Experiential Marketing terhadap Kepuasan Nasabah}

Dari hasil penelitian yang dilakukan ditemukan bahwa kepuasan nasabah terhadap experiential marketing BMT di Kota Palembang terbentuk karena lembaga ini mampu memberikan pengalaman atas keuntungan atau kelebihan yang didapat dari produk itu sendiri serta juga membangkitkan emosi dan perasaan secara langsung melalui lima pendekatan yaitu sense, feel, think, act, dan relate. Pengalaman ini sangatlah berbeda dengan sistem pemasaran tradisional yang berfokus pada fungsi dan keuntungan sebuah produk. Disini terlihat jelas pengalaman konsumen yang meliputi sense karena tampilan desain kantor dan seragam karyawan yang menarik serta memiliki letak kantor yang strategis, feel karena nasabah merasa senang, bangga, dan adanya perasaan positif ketika menggunakan jasa layanan di BMT, kemudian dikaitkan dengan think atas citra dan kemanan atas uang yang di tabung, dan act atas kegunaannya dalam membantu merubah gaya hidup menjadi lebih teratur dalam hal pengelolaan keunganan. Hal-hal itulah yang menjadi kekuatan bagi BMT di Kota Palembang untuk meningkatkan kepuasan konsumennya, sehingga pada akhirnya mampu menciptakan loyalitas terhadap BMT itu sendiri.

\section{Pengaruh Kualitas Pelayanan terhadap Kepuasan Nasabah}

Hasil penelitian dari data angket yang disebarkan kepada 100 responden nasabah BMT di Kota Palembang menunjukkan bahwa kualitas pelayanan yang dibangun oleh BMT di Kota palembang berpengaruh signifikan terhadap kepuasan nasabah. Hasil penelitian ini sesuai dengan penelitian yang dilakukan oleh Ari Prasetio (2012) dan Husnul Khotimah (2015) menyebutkan bahwa terdapat pengaruh yang signifikan pada salah satu variabel penelitiannya yaitu kualitas pelayanan terhadap variabel Kepuasan Pelanggan. Adanya Brand Trust, kepuasan para pelanggan pun dapat terjaga. Kepuasan terbangun karena harapan dan dapat bertindak sesuai dengan kebutuhan dan keinginan pelanggan, jika harapan tersebut sesuai dengan yang diinginkan pelanggan maka saat itu juga pelanggan akan puas. Hal ini juga sesuai dengan teori yang dikemukakan oleh Walker dalam Hasan (2009) bahwa kepuasan dapat terjadi bila produk yang dirasakan dengan yang diprediksi sebelum dibeli/dikonsumsi dapat sesuai dengan harapan bahkan melebihi dari dugaan pelanggan.

\section{Pengaruh Experiential Marketing terhadap Loyalitas Nasabah}

Hasil pengujian pengaruh experiential marketing terhadap loyalitas nasabah pada BMT di Kota Palembang sehingga $\mathrm{H}_{3}$ ditolak dan $\mathrm{Ha}$ diterima. Artinya ada pengaruh antara experiential marketing terhadap loyalitas nasabah. Hasil analisis jalur menunjukkan bahwa variabel experiential marketing memiliki pengaruh langsung dan signifikan terhadap variabel loyalitas pelanggan. Hal ini dibuktikan dari hasil penelitian yang menyatakan koefisien jalur variabel experiential marketing terhadap variabel loyalitas pelanggan sebesar 0,414 dengan probabilitas 0,001 $(p<0,05)$. Hal ini menunjukkan bahwa pengalaman baik tidak terlupakan yang dirasakan oleh pelanggan dapat menciptakan pelanggan yang loyal. Loyalitas 
pelanggan Jatim Park 1 ditunjukan dengan melakukan kunjungan ulang ke tempat wisata ini minimal dua kali. Seperti yang diungkapkan Bendapudi \& Berry (1997) mengungkapkan loyalitas pelanggan dalam pemasaran jasa didefinisikan sebagai respon yang terkait erat dengan janji untuk memegang komitmen yang mendasari relasi yang berkelanjutan dan tercermin dalam pembelian ulang dari penyedia jasa yang sama (Tjiptono \& Chandra, 2011). Hasil penelitian ini sejalan dengan penelitian Saraswati (2013).

\section{Pengaruh Kualitas Pelayanan Terhadap Loyalitas Nasabah}

Hasil analisis menunjukan bahwa kualitas layanan tidak berpengaruh terhadap loyalitas pelanggan. Artinya perubahan peningkatan kualitas layanan searah positif, tidak nyata terhadap peningkatan loyalitas pelanggan. Pelanggan yang datang ke BMT kurang mendapatkan pelayanan yang baik dikarenakan factor kurangnya pemahaman karyawan BMT terhadap produk yang ditawarkan serta tidak adanya layanan ATM, tentunya akan membuat nasabah merasakan ketidak nyamanan dan pada akhirnya membuat tidak loyal terhadap BMT. Hasil penelitian ini mendukung pendapat Kottler (1997) dan penelitian Shyh-Jane (2011); Wei-Ming (2011); Chenet (2010); Kassim (2010); Norizan (2009); dan Sunil (2008) bahwa kualitas jasa (pelayanan) harus dimulai dari kebutuhan pelanggan dan berakhir dengan kepuasan pelanggan, hubungan tersebut secara teoris maupun empiris adalah positif.

\section{Pengaruh Kepuasan Nasabah Terhadap Loyalitas Nasabah}

Hasil pengujian pengaruh kepuasan nasabah terhadap loyalitas nasabah BMT di Kota Palembang sehingga $\mathrm{H}_{5}$ diterima dan $\mathrm{H}_{0}$ ditolak. Artinya ada pengaruh antara kepuasan nasabah terhadap loyalitas nasabah. Hasil penelitian ini menunjukkan bahwa kepuasan pelanggan memiliki nilai pengaruh tertinggi dan signifikan terhadap loyalitas nasabah. Menurut Kotler (1997) bahwa kepuasan adalah hasil yang dirasakan oleh pembeli yang mengalami kinerja sebuah perusahaan yang sesuai dengan harapannya. Pelanggan merasa puas kalau harapan mereka terpenuhi, dan merasa sangat gembira kalau harapan pelanggan terlampaui. Adanya kepuasan yang sesuai dengan harapan pelanggan, membuat pelanggan menginginkan kembali untuk kepuasan secara berulang-ulang dan hal inilah yang memicu loyalitas pelanggan pada akhirnya. Menurut Walker (2008) kepuasan pelanggan dapat didefinisikan sebagai suatu keadaan dimana kebutuhan, keinginan, dan harapan pelanggan dapat terpenuhi melalui produk yang dikonsumsi. Secara umum, kepuasan pelanggan dapat dikatakan sebagai perasaan senang atau kecewa seseorang dari perbandingan antara produk yang dibeli sesuai atau tidak dengan harapannya.

\section{Pengaruh Experiential Marketing Terhadap Loyalitas Nasabah Melalui Kepuasan Nasabah sebagai Variabel Intervening}

Berdasarkan hasil analisis penelitian di atas maka experiential marketing berpengaruh terhadap loyalitas dengan kepuasan sebagai variabel intervening. Hal ini dapat dijelasakan karena tidak adanya efek langsung dari variabel experiental marketing terhadap loyalitas pelanggan dengan kepuasan sebagai variabel intervening. Loyalitas yang dibentuk dari experiential marketing yang dirasakan nasabah BMT di Kota Palembang akan lebih tinggi jika pelanggan telah merasakan kepuasan terlebih dahulu. Indikator yang digunakan untuk mengukur variabel Experiential marketing yaitu sense, feel, think, act, relate, akan lebih tinggi pengaruhnya pada loyalitas yang diberikan oleh 
pelanggan kepada orang lain jika pelanggan telah merasakan kepuasan.

\section{Pengaruh Kualitas Pelayanan terhadap Loyalitas Nasabah Melalui Kepuasan sebagai Variabel Intervening}

Berdasarkan hasil penelitian tersebut menunjukkan bahwa kualitas layanan BMT di Kota Palembang mampu memberikan tingkat kepuasan Nasabah yang sangat besar sehingga nasabah menjadi sangat loyal bahkan merekomendasikan pada orang lain serta dengan adanya kualitas yang baik dalam pemberian layanan jasa, menumbuhkan kepuasan bagi konsumen. Hal tersebut sesuai dengan teori yang menyatakan perusahaan yang dapat memberikan layanan yang berkualitas dan konsumen merasa mendapatkan kepuasan maka akan tercipta loyalitas konsumen, dan sebaliknya (Kotler, 1997). Teori tersebut juga didukung dengan pendapat Sviokla (Lupioadi, 2001) yang menyatakan bahwa kualitas layanan yang diberikan oleh perusahaan dapat menciptakan suatu persepsi positif dari konsumen terhadap perusahaan dan menghasilkan suatu kepuasan serta loyalitas konsumen. Kualitas layanan yang ditampilkan oleh suatu perusahaan merupakan salah satu stimulus yang menciptakan konsumen melakukan transaksi kembali dengan perusahaan jasa tersebut. Karyawan BMT selalu memberikan senyum dan sapaan kepada setiap nasabah yang menggunakan jasa BMT, dan BMT juga berusaha memenuhi keinginan nasabah (Indrawati, 2011).

\section{Kesimpulan}

Penelitian ini menyimpulkan bahwa pertama, variabel experiential marketing dan kualitas pelayanan berpengaruh terhadap variabel kepuasan nasabah BMT di Kota Palembang. Kedua, variabel experiential marketing berpengaruh terhadap variabel loyalitas nasabah. Ketiga, variabel kualitas pelayanan tidak berpengaruh terhadap variabel loyalitas nasabah. Keempat, variabel kepuasan nasabah berpengaruh terhadap variabel loyalitas nasabah. Kelima, variabel experiential marketing berpengaruh terhadap variabel loyalitas nasabah dengan variabel kepuasan nasabah sebagai variabel intervening BMT di Kota Palembang. Dan keenam, variabel kualitas pelayanan berpengaruh terhadap variabel loyalitas nasabah dengan variabel kepuasan nasabah sebagai variabel intervening.

\section{Daftar Pustaka}

Chenet, P., Dagger, T. S., \& O’Sullivan, D. (2010). Service quality, trust, commitment and service differentiation in business relationships. Journal of Services Marketing.

Huang, Y.-Y., Li, S.-J., \& Yang, M. M. (2011). How and when service quality and satisfaction simultaneously influence purchase intentions? Health Services Management Research, 24(3), 121-129.

Indrawati, A. (2011). Pengaruh Kualitas Layanan Lembaga Pendidikan terhadap Kepuasan Konsumen. Jurnal Ekonomi Bisnis, 16(1), 25-35.

Kassim, N., \& Asiah Abdullah, N. (2010). The effect of perceived service quality dimensions on customer satisfaction, trust, and loyalty in e-commerce settings. Asia Pacific Journal of Marketing and Logistics, 22(3), 351-371. https://doi.org/10.1108/13555851011062269

Khotimah, K., \& Chasanah, U. (2015). Analisis Pengaruh Kualitas Pelayanan Terhadap Kepuasan Konsumen Pada Mato Kopi. STIE Widya Wiwaha.

Kotler, P. (1997). Marketing management: Analysis, planning, implementation and control.

Norizan, M. K., \& Salaheldin, I. (2009). Investigating the complex drivers of loyalty in e-commerce settings. Measuring Business Excellence, 13(1), 56-71.

Ou, W., Shih, C., Chen, C., \& Wang, K. (2011). Relationships among customer loyalty programs, service quality, relationship quality and loyalty. Chinese Management Studies.

Parasuraman, A., Zeithaml, V. A., \& Berry, L. (1988). SERVQUAL: A multiple-item scale 
for measuring consumer perceptions of service quality. 1988, 64(1), 12-40.

Prasetio, A. (2012). Pengaruh kualitas pelayanan dan harga terhadap kepuasan pelanggan. Management Analysis Journal, 1(1).

Sahadev, S., \& Purani, K. (2008). Modelling the consequences of e-service quality. Marketing Intelligence \& Planning, 26(6), 605-620. https://doi.org/10.1108/02634500810902857

Saraswati, R. (2013). Pengaruh Experiential Marketing terhadap Loyalitas (Studi Pada Pelanggan Taman Indie Resto Malang). Jurnal Administrasi Bisnis, 6(1).

Tjiptono, F., \& Chandra, G. (2011). Service Quality $\&$ Satifaction. Andi.

Tugimin, A. J., Saadan, R., Yusof, M. N., \& Hasan, H. (2009). Perkaitan Persepsi Terhadap Organisasi Dengan Kepuasan Kerja Dalam Kalangan Guru Penolong Kanan Sekolah Menengah Negeri Melaka. Journal of Human Capital Development (JHCD), 2(1), 65-75.

Walker, A. G., Smither, J. W., \& Waldman, D. A. (2008). A longitudinal examination of concomitant changes in team leadership and customer satisfaction. Personnel Psychology, 61(3), 547-577. https://doi.org/10.1111/j.17446570.2008.00122.x 